\title{
Three-dimensional and Power Doppler Ultrasound of the Follicle and Endometrium on the Day of hCG Administration
}

\author{
Sonal Panchal, CB Nagori \\ Dr Nagori's Institute for Infertility and IVF, 2nd Floor Kedar, Opp. Krupa Petrol Pump \\ Nr. Parimal Garden, Ellisbridge, Ahmedabad, Gujarat, India
}

\begin{abstract}
The advances in ultrasound technology has changed the management of infertility. With the advent of color Doppler, pulse Doppler, 3D US and then 3D power Doppler the previously unexplained causes of failure of fertilization and implantation can now be explained. 3D and 3D power Doppler can now be used for the assessment of the maturity of the follicle and receptivity of the endometrium and can give better idea about the functional maturity of the follicle and the endometrium, to decide the timing of hCG administration for all assisted reproductive techniques for better pregnancy rates. The accuracy of diagnosis and monitoring of infertility treatments such as ovulation induction has greatly increased because of the availability of sophisticated ultrasound technology and equipment. ${ }^{1}$
\end{abstract}

Key words: 3D power Doppler ultrasound, follicular assessment, endometrial evaluation.

\section{INTRODUCTION}

The assessment of the follicular maturity and the endometrial receptivity and the time of Human Chorionic Gonadotropin (hCG) is one of the key factors for success of all ART procedures. The follicular maturity can be assessed by the estradiol levels, but frequent assessment of blood estradiol level is a cumbersome procedure. Since the advent of the transvaginal Ultrasound this has been a preferred method for the assessment of the follicle and the endometrium. Earlier the follicular size of 16 to $18 \mathrm{~mm}$ and the endometrial thickness of $8 \mathrm{~mm}$ were considered as appropriate for Human Chorionic Gonadotropin administration for ovulation trigger. This tells only about the anatomical maturity of the follicle and the endometrium. But maturation of the follicle and the endometrium, ovulation and luteinization is a process of multiple biochemical, morphological and vascular changes. The vascular changes are reflection of the biochemical changes and can be studied by color Doppler. 3D ultrasound gives a better assessment of the follicular and endometrial size, that is the anatomical maturity, than 2D ultrasound and 3D power Doppler gives not only qualitative but also quantitative idea of global vascularity, that is the reflection of functional/physiological maturity.

\section{FOLLICULAR ASSESSMENT}

Antral follicles in the early follicular stage of the menstrual cycle start growing under the effect of endogenous or exogenous $\mathrm{FSH}$. The follicle which reaches a size of $10 \mathrm{~mm}$ is the dominant follicle and then grows at the pace of app. $2 \mathrm{~mm}$ per day till it reaches the size of $18 \mathrm{~mm}$. The growing follicle can be assessed by transvaginal sonography. A mature follicle should be round, thin walled with no internal echoes. The shape changes from round to polygonal when there are multiple follicles due to pressure effect from adjacent follicles. In such follicles the follicular volume would have to be considered in stead of a single diameter which is calculated as $(\mathrm{D} 1 \times \mathrm{D} 2 \times \mathrm{D} 3) \times 0.52$, where D1, D2 and D3 are three diameters of follicles in perpendicular planes. The follicle shape may become ellipsoid if too much pressure is applied on the transvaginal probe. The follicular diameter is measured when the follicle is seen as a rounded structure, or at least three measurements must be taken perpendicular to each other to take a mean. A mature follicle is 16 to $18 \mathrm{~mm}$ (Fig. 1) and shows a thin hypoechoic rim surrounding the follicle and sometimes (about 35 to 40\%) cumulus like shadow may be seen.

On color Doppler the follicle shows blood vessels covering at least 3/4th of the follicular circumference (Figs 1 and 3) and on pulse Doppler these blood vessels show an RI of 0.4 to $0.48^{2}$ and PSV of $>10 \mathrm{~cm} / \mathrm{sec}$ (Figs 2 and 3). Higher RI indicates higher resistance flow to the follicle meaning lower flow during diastolic phase and so reduced phasic oxygen supply to the ovum and hence lack of maturity. Lower PSV again indicates lower blood supply and hence lack of maturity. It has been quoted in a study by Nargund et $\mathrm{al}^{3,4}$ that embryos produced by fertilization of the ova obtained from the follicles which had a perifollicular PSV of $<10 \mathrm{~cm} / \mathrm{sec}$, are less likely to be grade I embryos and also have higher chance of chromosomal malformations. Our unpublished data of more than 1000 IUI cycles has shown that when the perifollicular RI $>0.53$ and PSV $<9 \mathrm{~cm} / \mathrm{sec}, 12$ hours before hCG injection, the conceptions rates were only $8.3 \%$ and $10 \%$ respectively as compared 


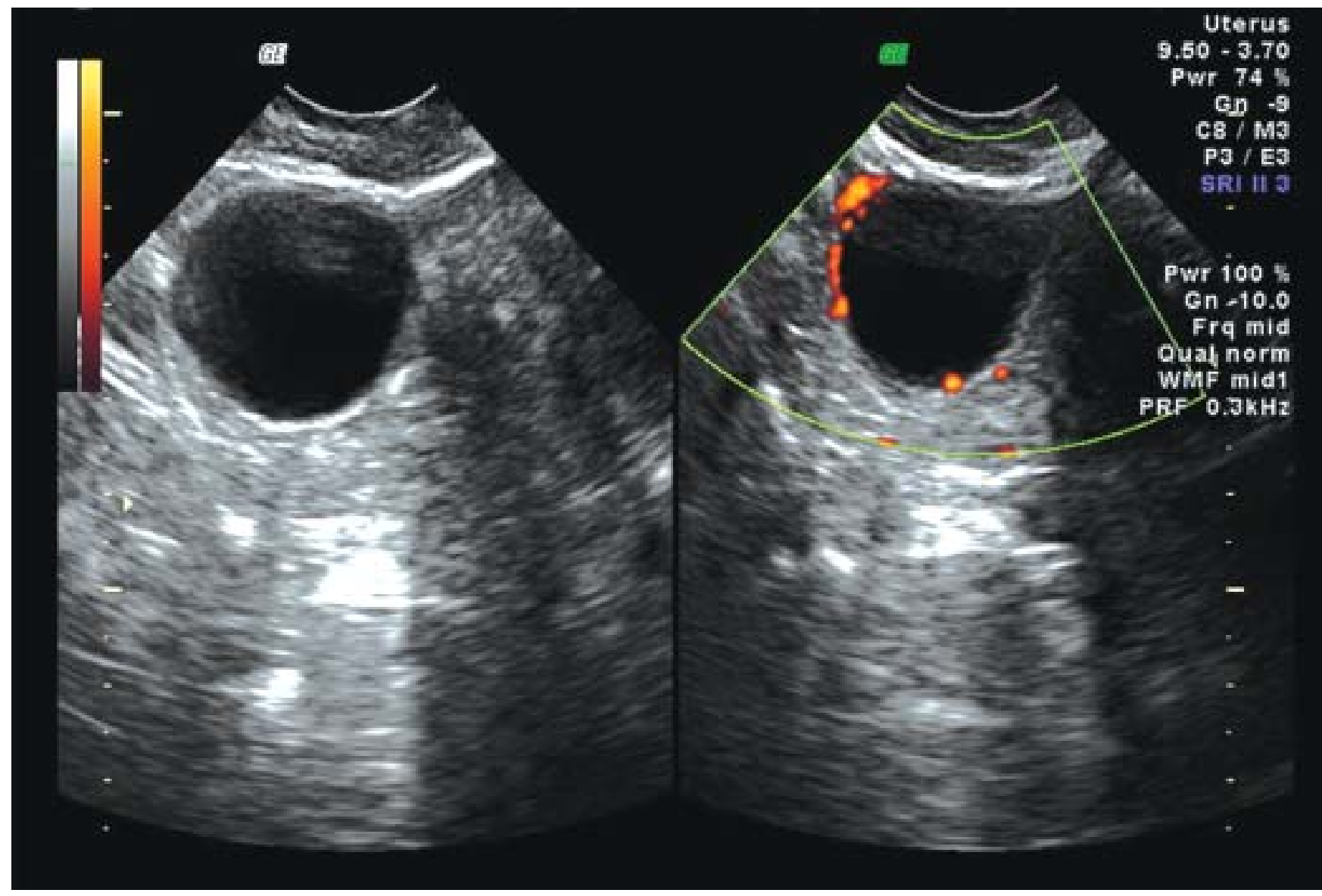

Fig. 1: Preovulatory follicle with 2D power Doppler

to $32.8 \%$ and $28.2 \%$ respectively and individually when perifollicular RI $<0.50$ and PSV $>11 \mathrm{~cm} / \mathrm{sec}$.

\section{Follicular Rl: (1025 cases)}

\begin{tabular}{lrrr}
\hline Foll. RI & $0.56-0.53$ & $0.53-0.50$ & $<0.50$ \\
Conc. & 05 & 71 & 170 \\
Non Conc. & 58 & 373 & 348 \\
\hline Total & 63 & 444 & 518 \\
\hline
\end{tabular}

\section{Follicular PSV: (1025 cases)}

\begin{tabular}{lrrrr}
\hline Foll. PSV & $<9$ & $9-10$ & $10-11$ & $>11$ \\
Conc. & 04 & 14 & 38 & 190 \\
NonConc. & 36 & 92 & 168 & 483 \\
\hline Total & 40 & 106 & 206 & 673 \\
\hline
\end{tabular}

(Conc.: Conceived cases, NonConc. : Nonconceived cases)
We have, therefore, always preferred to wait with no extra medication when patient is on clomiphene citrate stimulation or continue with the same dose of Gonadotropin till we get proper perifollicular RI and PSV, though sometimes the follicular size may reach up to $22 \mathrm{~mm}$. Almost $90 \%$ of the times the desired RI and PSV are reached by the time follicular size is $20 \mathrm{~mm}$ maximum.

We use 3D USG and 3D power Doppler for the assessment of these follicles. We studied 500 IUI cycles which were all monitored for ovulation by 2D and color Doppler. When the follicles appeared mature as per the above mentioned features, 3D and 3D power Doppler was done for all and the values of 3D and 3D power Doppler indices were studied and plotted on the graphs for conception and non-conception cycles.

We use Voluson 730 Expert (GE) for our studies. Once the, follicles of $>16 \mathrm{~mm}$ for Gonadotropin stimulation or $>18 \mathrm{~mm}$ for CC stimulated cycle is seen and assessed by color Doppler, the volume box is switched on. The size of the volume box should be enough to include the whole follicle and at least 
Three-dimensional and Power Doppler Ultrasound of the Follicle and Endometrium on the Day of hCG Administration

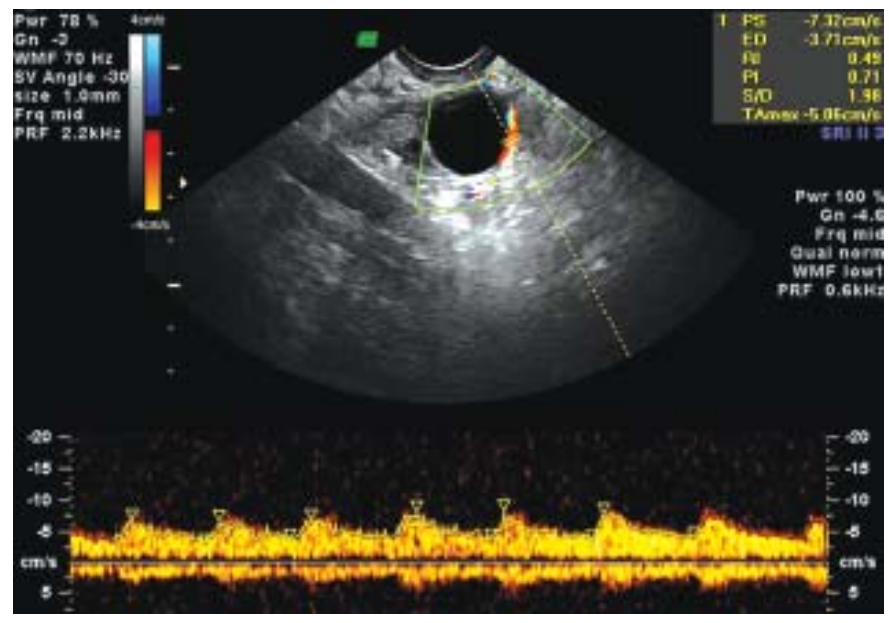

Fig. 2: Preovulatory follicle with pulse Doppler showing low resistance flow

a surrounding 5 to $7 \mathrm{~mm}$ margin. The angle of the volume should be large enough to cover the whole follicle from edge to edge. The acquired volume is seen as follicle in three perpendicular

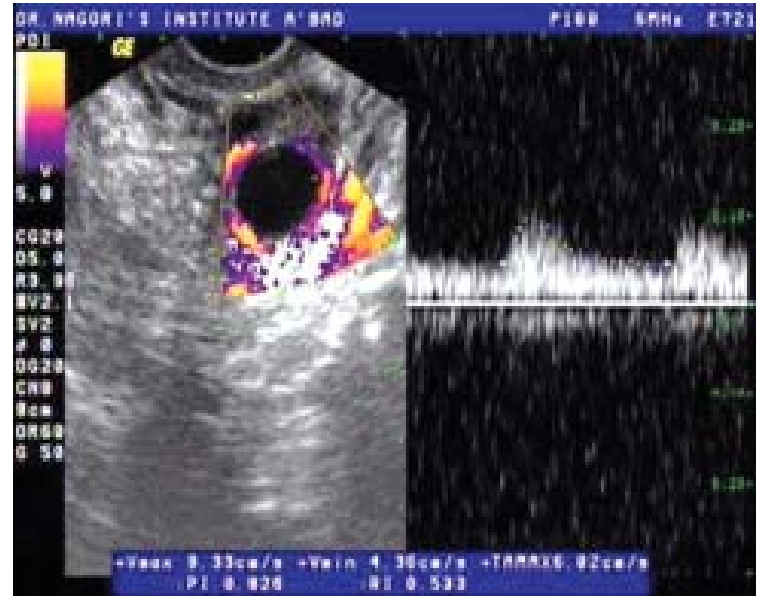

Fig. 3: Preovulatory follicle with vascular ring surrounding the follicle and pulse Doppler waveform

planes on the screen. Using the Vocal Soft ware with $15^{\circ}$ angle the follicle is traced at its circumference at every $15^{\circ}$ rotation (Fig. 4) and at the end the command 'done' is given, the Region

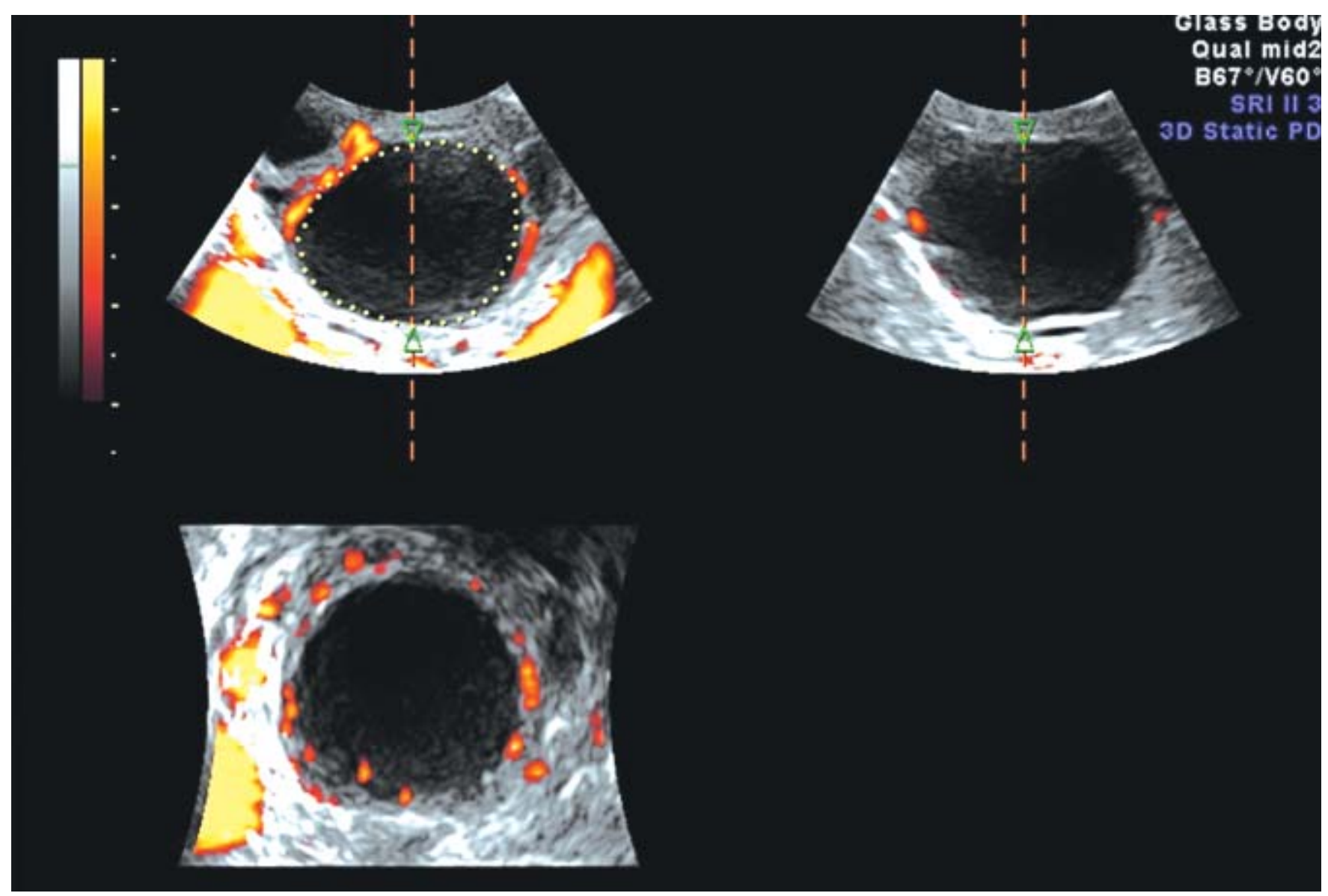

Fig. 4: Calculating follicular volume by Vocal 


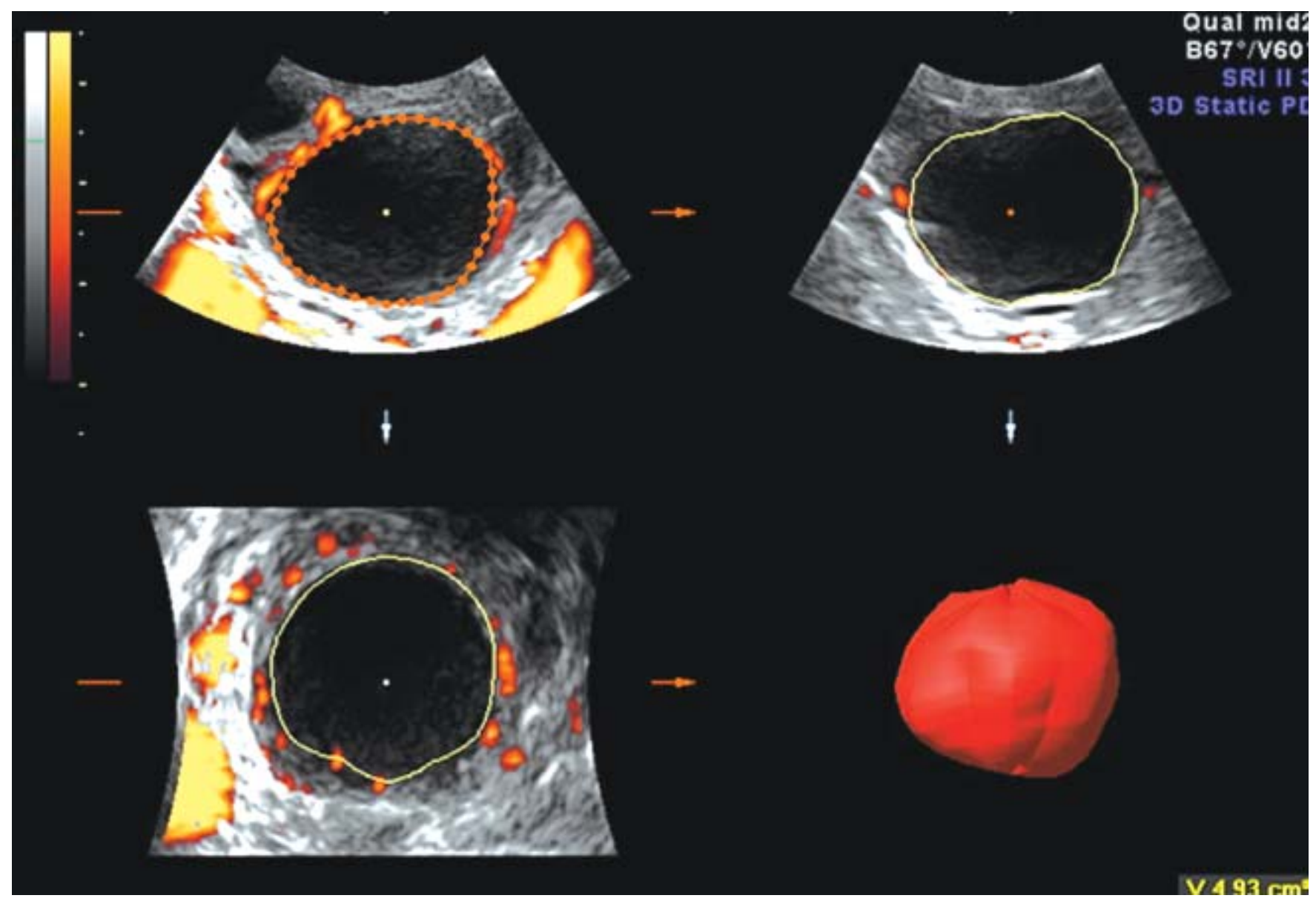

Fig. 5: Follicular volume by vocal

of interest (ROI) is ultimately accepted, or any corrections required may be made and the machine then calculates the volume of the follicle. On 3D the follicular volume of 3 to $7.5 \mathrm{cc}$ has been found to be optimum in our study ${ }^{27}$ (Fig. 5). This agrees with the study by Wittmack et $\mathrm{al}^{5}$ which says that : In IVF-ET cycles, follicles with mean follicular diameter of 12 to $24 \mathrm{~mm}$ are associated with optimal rates of oocyte recovery, fertilization and cleavage. This corresponds to the follicular volumes of between 3 and $7 \mathrm{ml}$. The accuracy of 3D US measurement of follicular volume compared to the standard 2D techniques by comparing the volume of individual follicles estimated by both methods with the corresponding follicular aspirates : using the formula of ellipse the limits of agreement between aspirates and calculated volume was +3.47 to -2.42 as compared to +0.96 to -0.43 when calculated by 3D US using VOCAL. ${ }^{6}$ This is because 3D US measurement is not affected by the follicular shape as the changing contours are outlined serially to obtain the specific volume measurement. Though the follicles of $<10$ $\mathrm{mm}$ in diameter, can not be assessed accurately by 3D US because limits of agreement are too wide in this range.
After the volume calculation the follicle is seen plane by plane in the acquired volume by translation and rotation, that is walking through the volume and rotating the volume. Or one can also use TUI (tomographic ultrasound imaging), in all three planes, with a slice thickness of $0.5 \mathrm{~mm}$, zoom the image so that only the follicle can be seen on each image and slices are examined one by one or in a set of 4 for the presence of cumulus like echo. If it is seen on one plane it is confirmed on the other two planes and also on the rendered image. Using the surface smooth or light gradient mode for rendering with high threshold can show beautiful cumulus (Fig. 6). We in our study of 500 IUI cycles have been able to locate the cumulus in $94.6 \%$ of cases in conception cycles and in 53\% of nonconception cycles by surface rendering usually and TUI ( $0.5 \mathrm{~mm}$ slices) sometimes. In IVF cycles also, we have been able to predict the number of ova that we would obtain on retrieval by the number of cumulus containing follicles. Feichtinger et al in their study have shown presence of cumulus in follicles $>15 \mathrm{~mm}$ by 3D US. ${ }^{7}$ Follicles without visualization of cumulus in all three planes are not likely to contain mature oocytes. Poehl et al also showed in their study that appearance of the intrafollicular 


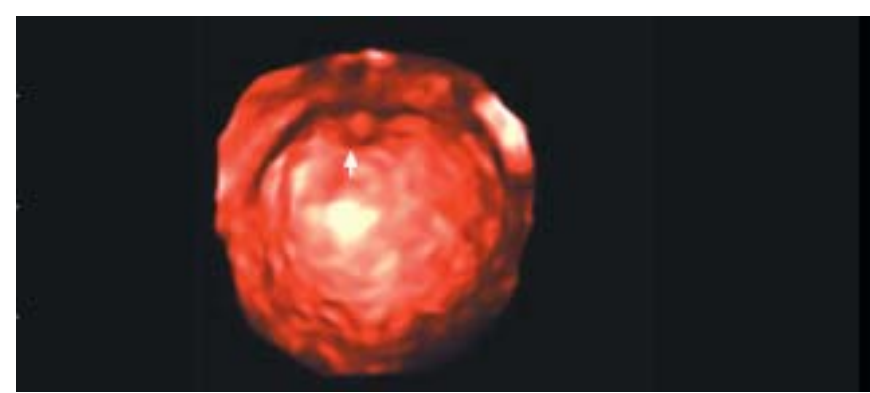

Fig. 6: Cumulus oophorus in preovulatory follicle

cumulus structures by 3D US was correlated with the recovery rate of the mature oocytes. ${ }^{8}$ They also found a significant correlation between the number of detected cumuli and the number of retrieved oocytes $(\mathrm{P}<0.0001)$, mature oocytes $(\mathrm{P}<$ $0.0001)$ and number of fertilized oocytes $(\mathrm{P}<0.0001)$. Therefore, visualization of the cumulus by 3D US is a positive indicator of mature oocytes in both IUI and IVF procedures and has been found to be an indicator of successful fertilization in IVF cycles also.

The follicular fluid concentrations of leptine, a follicular angiogenesis related factor are inversely related to the stromal blood flow index. ${ }^{9}$ It has also been suggested that the follicles containing oocytes capable to produce a pregnancy have a perifollicular vascular network more uniform and distinctive. ${ }^{10}$

After having measured the volume of the follicle and looking for the presence of the cumulus, we switch over to power Doppler. The PRF settings are fixed at 0.3 always and again a $3 \mathrm{D}$ volume with power Doppler is taken, the volume angle same as that for the follicular volume is selected. Again on the screen, the follicle is seen in three perpendicular planes but this time with blood vessels as seen on power Doppler. Again switch on the vocal and calculate the follicular volume. At the end of the last scroll around the follicle, click the 'done' switch and the options are open to accept the ROI or to select one of the options for the shell volume. We select an option for the outside shell with the wall thickness of $2 \mathrm{~mm}$, which has been found to be the most appropriate to include the perifollicular vessels (Figs 7 and 8). Then accept this and switch on the volume histogram. When this volume is accepted it gives you the follicular volume as the reference volume, the shell volume as the volume of the wall and the whole combined volume. So for all practical purposes we usually omit taking the volume of the follicle without the power Doppler first as this vocal calculation with power Doppler will give us the follicular volume also. More

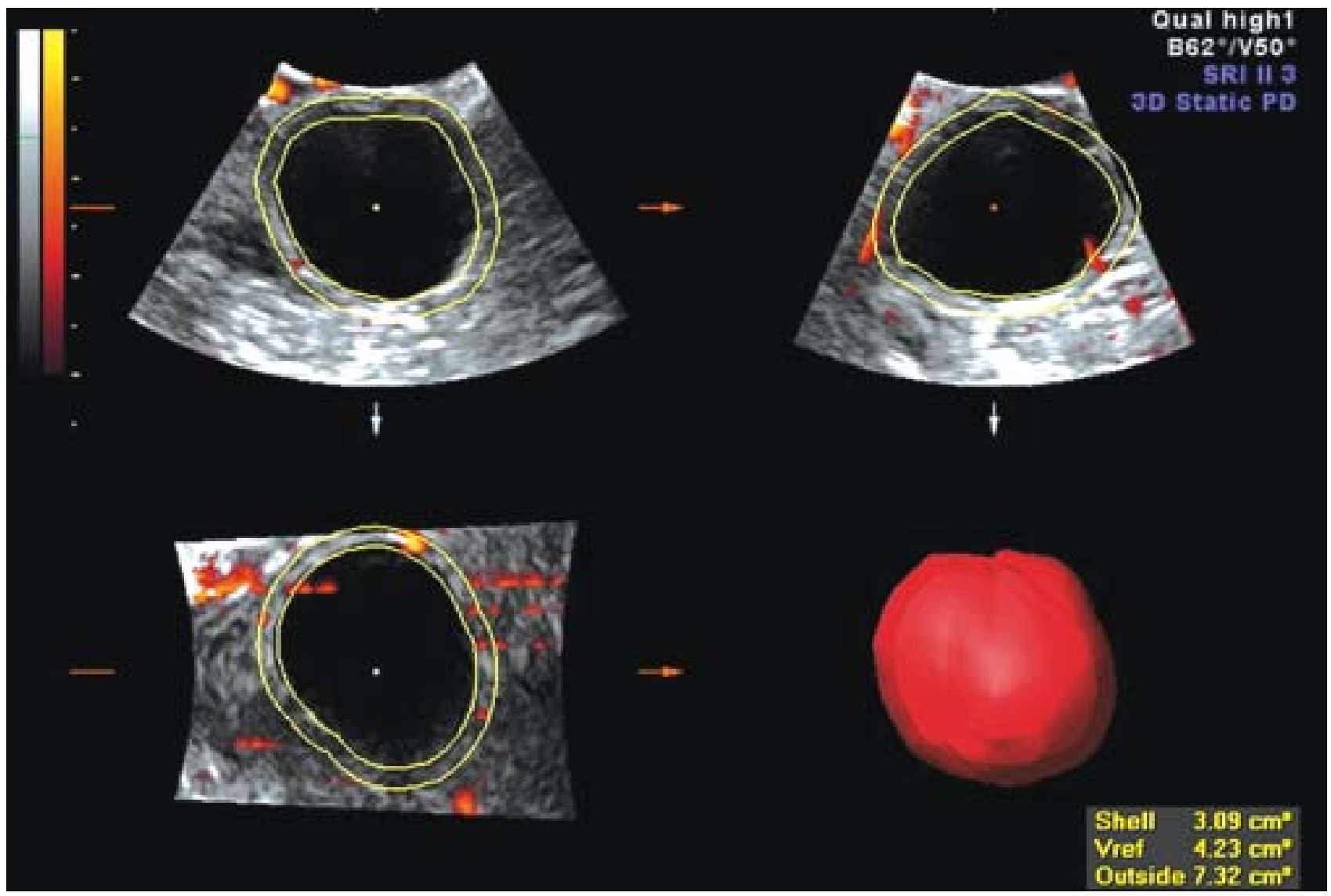

Fig. 7: Calculating the shell volume of the follicle for perifollicular 3D-PD assessment 


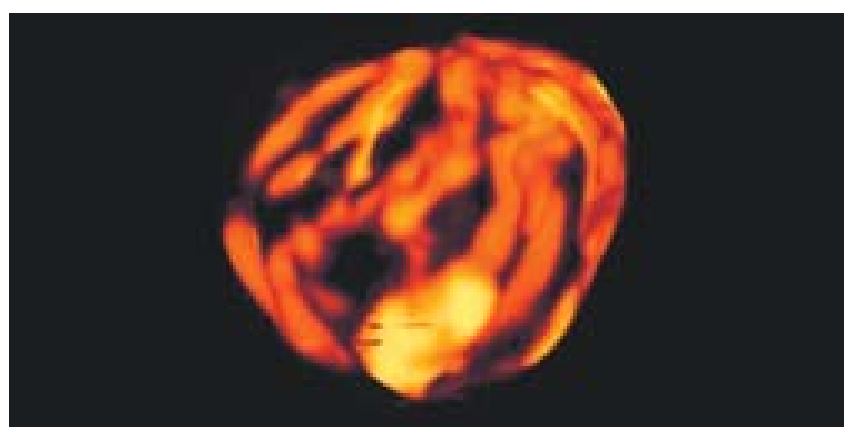

Fig. 8: Angiomode of the perifollicular vascularity

over the same volume can be assessed for the cumulus also as described earlier and that saves time spent on each patient for acquiring and calculating one extra volume dataset. So then when we switch over to volume histogram, we get a graph which shows the calculation of the gray voxels and the colored voxels in the given volume and these values are displayed on the screen as VI, FI and VFI values. VI indicates the abundance of the color voxels in the given volume, FI indicates the intensity of the color in the given volume and VFI is the ratio of the abundance and intensity, meaning it gives idea about the general perfusion status of the given volume (Fig. 9). This means volume histogram or the 3D power Doppler indices gives the quantitative assessment of the vascularization and perfusion of the given volume. So after calculating the volume of the follicle and the shell volume when we switch on the volume histogram, the VI, FI and VFI values that we get are the perifollicular vascularization and perfusion indices. This gives a more global idea about the follicular vascularity than the 2D power Doppler.

In our study ${ }^{27}$ we have found perifollicular VI of between 6 and 20 and perifollicular FI $>35$ as most optimum. $68.4 \%$ of patients conceived when the VI was between 6 and 18 and 50\% when it was between 18 and 20. However the pregnancy rates were $<25 \%$ when VI was $<6$ and only $7.4 \%$ when VI was $>$ 20. It was only $7.4 \%$ of patients with FI $<27$ who conceived where as beyond 27 , the conception rates rose consistently. It was $50 \%$ with FI between 27 and 35, $70 \%$ when FI was between 35 and 43 and almost all patients had conceived when FI was > 43. (Fig. 10).

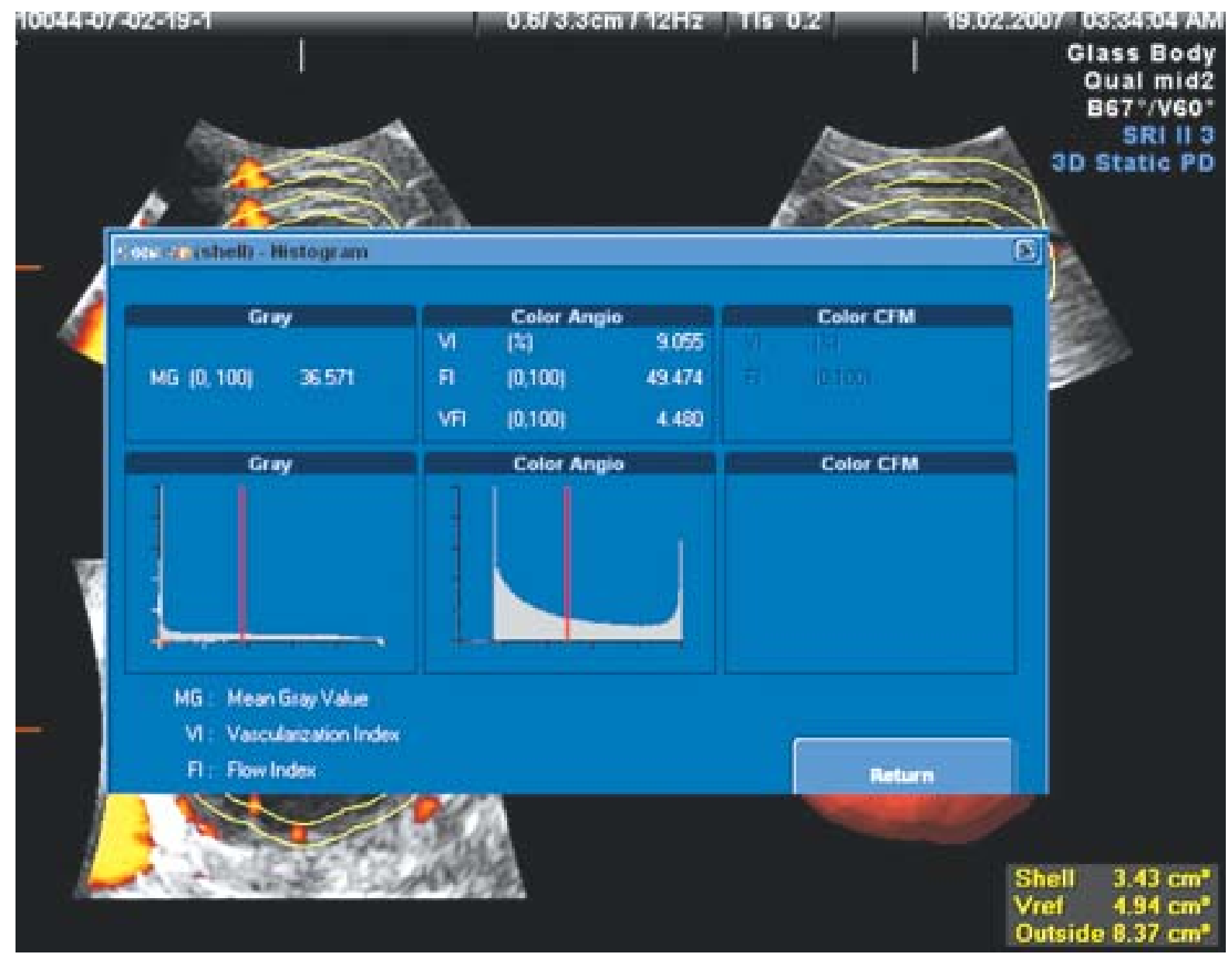

Fig. 9: Histogram for perifollicualr flow giving VI, FI and VFI values 

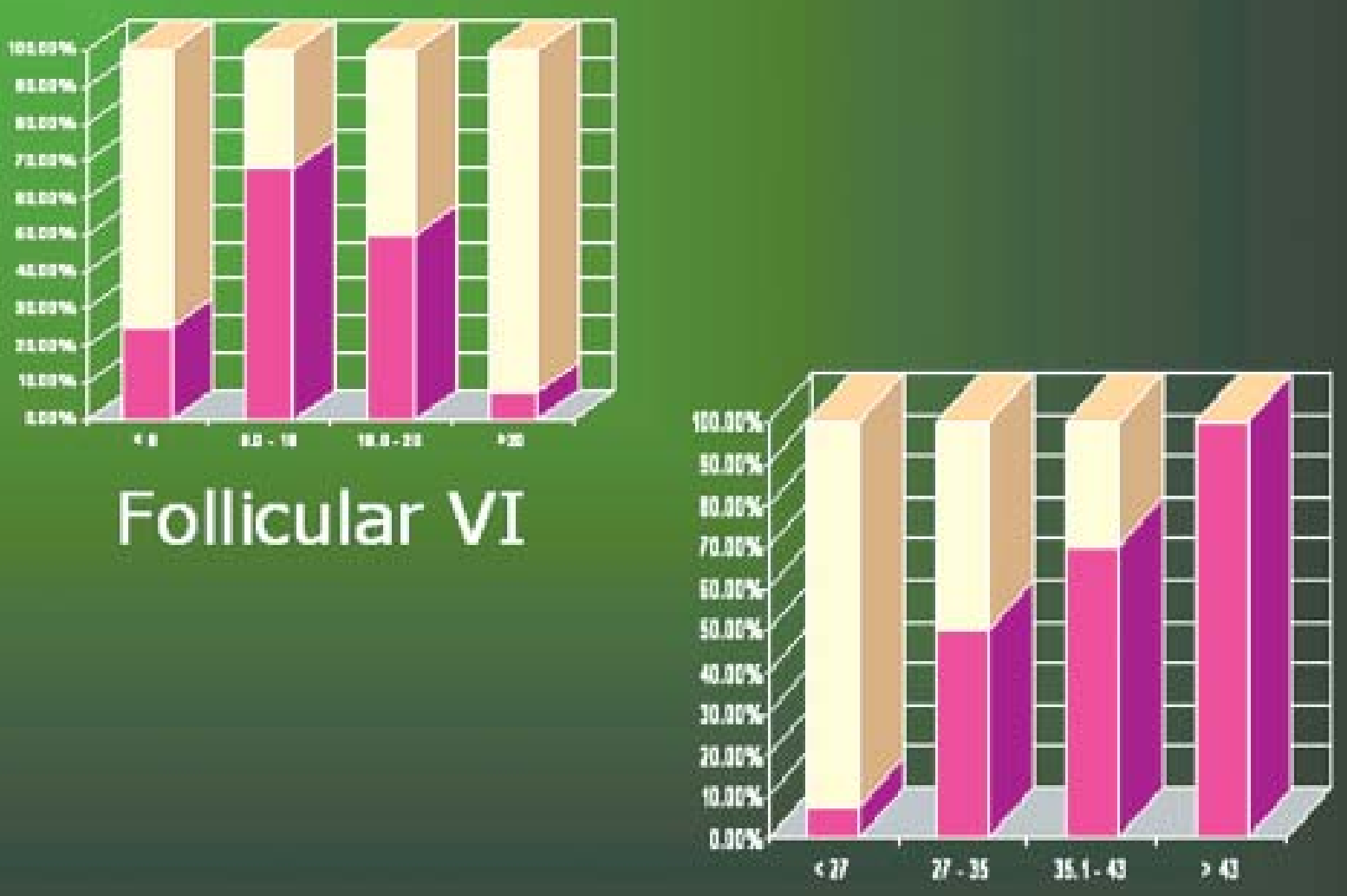

\section{Follicular FI}

Fig. 10: Pre HCG perifollicular 3D-PD values

Follicular Volume: ( 500 cases)

\begin{tabular}{lrrrr}
\hline Foll. Vol. & $<3$ & $3-5$ & $5.1-7$ & $>7$ \\
Conc. & 15 & 94 & 85 & 20 \\
NonConc. & 46 & 89 & 66 & 95 \\
\hline Total & 61 & 183 & 151 & 115 \\
\hline
\end{tabular}

Follicular VI: ( 500 cases)

\begin{tabular}{lrrrr}
\hline Foll. VI & $<6$ & $6-18$ & $18.1-20$ & $>20$ \\
Conc. & 6 & 115 & 83 & 10 \\
Non Conc & 20 & 55 & 83 & 128 \\
\hline Total & 26 & 170 & 166 & 138 \\
\hline
\end{tabular}

Follicular Fl: (500 cases)

\begin{tabular}{lrrrr}
\hline Foll. FI & $<27$ & $27-35$ & $35.1-43$ & $>43$ \\
Conc. & 12 & 100 & 76 & 26 \\
Non Conc. & 153 & 100 & 32 & 1 \\
\hline Total & 165 & 200 & 108 & 27 \\
\hline
\end{tabular}

Meaning that even when the follicle appeared mature according to the 2D US and color and pulse Doppler parameters, the pregnancy rates were significantly better only when the follicular volume was between 3 and $7.5 \mathrm{cc}$, cumulus was present and the perifollicular VI and FI values were as mention above.

A study by Kupesic and Kurjak shows that when the ratio of follicular volume to blood flow index (FV/FI) is between 0.4 and 0.6 the pregnancy rates are $39 \%$, if $>0.6$, it is $52 \%$ and when $<0.4$ is only $21 \%{ }^{11}$ 
This explains us the failure to achieve pregnancy in IUI cycles and failure to retrieve ova or achieve fertilization in IVF cycles even when hCG is given after proper assessment of follicle by 2D and color Doppler US. Although it is possible to assess the follicular flow as expressed by the peak systolic velocity and perifollicular color map, ${ }^{12}$ it is the $3 \mathrm{D}$ power Doppler which proves the most precise information about the vascularization and follicular blood flow. ${ }^{13}$

\section{ENDOMETRIAL EVALUATION}

Endometrium, like follicle, is assessed by transvaginal 2D US and color Doppler as a fertile soil is equally important as a good quality seed for the implantation to occur. On TVS an endometrial thickness of minimum $6 \mathrm{~mm}$ is required on the day of hCG, but we have found $8 \mathrm{~mm}$ to be optimum. Endometrial thickness has more negative predictive value for implantation.

The multilayered endometrial pattern is also essential. The endometrium is being graded as the best when it is a triple line endometrium with the intervening area is as hypoechoic as the anterior myometrium. The echogenecity is attributed to the development of multiple vessels in the endometrium producing multiple tissue interfaces and therefore causing the echogenecity and due to the glycogen storage in the endometrial epithelium (Fig. 11). The endometrium is graded as intermediate or grade 2 (Fig. 12) when it is multilayered or triple line with the intervening area hypoechoic. In Grade 3 or the most unfavorable endometrium would be a homogenous endometrium. Though some studies have shown no significant difference in pregnancy rates amongst different morphological patterns. In all the healthy endometria, the endometrio-myometrial interface is always seen as a clear hypoechoic halo surrounding the whole endometrium.

As for follicle, for endometrium also the physiological maturity is essential which again can be assessed by color Doppler. Segmental uterine artery perfusion demonstrates significant correlation with hormonal and histological markers of uterine receptivity, reaching the highest sensitivity for subendometrial blood flow. ${ }^{14}$ On color Doppler the endometrium which is mature shows vascularity in zone 3 and 4 or may be said in subendometrial and endometrial layers (Fig. 13). The zones of vascularity are defined according to Applebaum ${ }^{15}$ as: zone 1 when the vascularity on power Doppler is seen only in the myometrium surrounding the endometrium, Zone 2 when vessels penetrate through the hyperechogenic endometrial edge, Zone 3 when it reaches internal hypoechogenic zone and zone 4 when they reach the endometrial cavity. The pregnancy rates related to the zones of vascular penetration: $26.7 \%$ for zone 1, 36.4\% for zone 2 and $37.9 \%$ for zone 3. Though in our unpublished data of more than 1000 IUI cycles, when color Doppler studies were done 12 hours before hCG injection, we have found only $7.3 \%$ pregnancy rates for

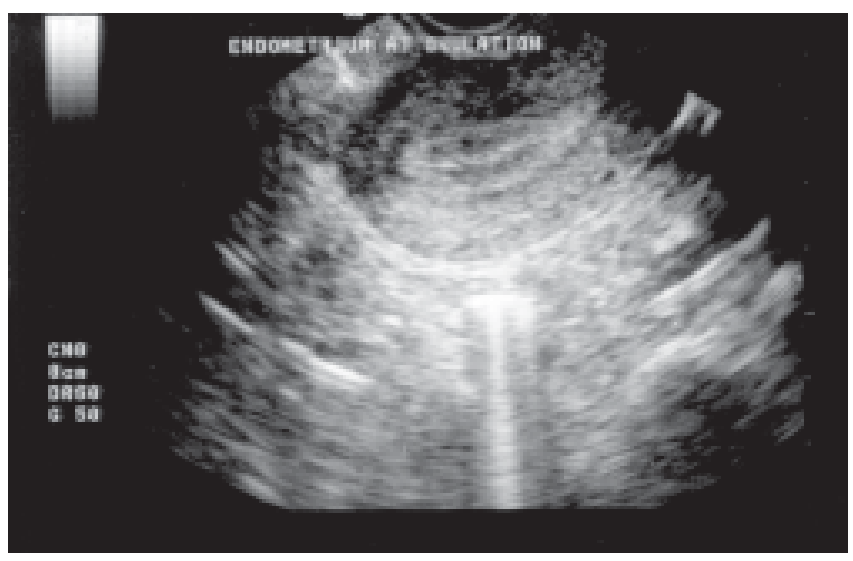

Fig. 11: Most receptive endometrium-multilayered

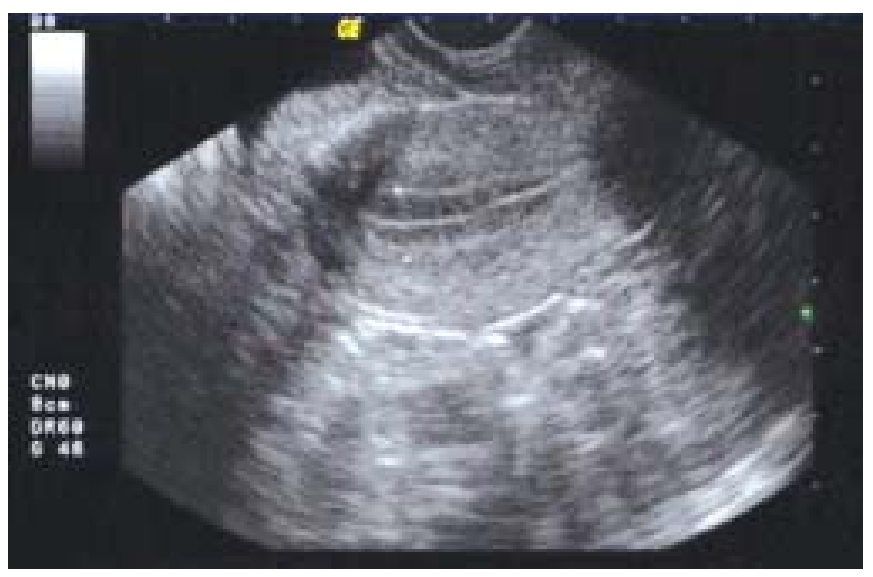

Fig. 12: Multilayered endometrium-intermediate

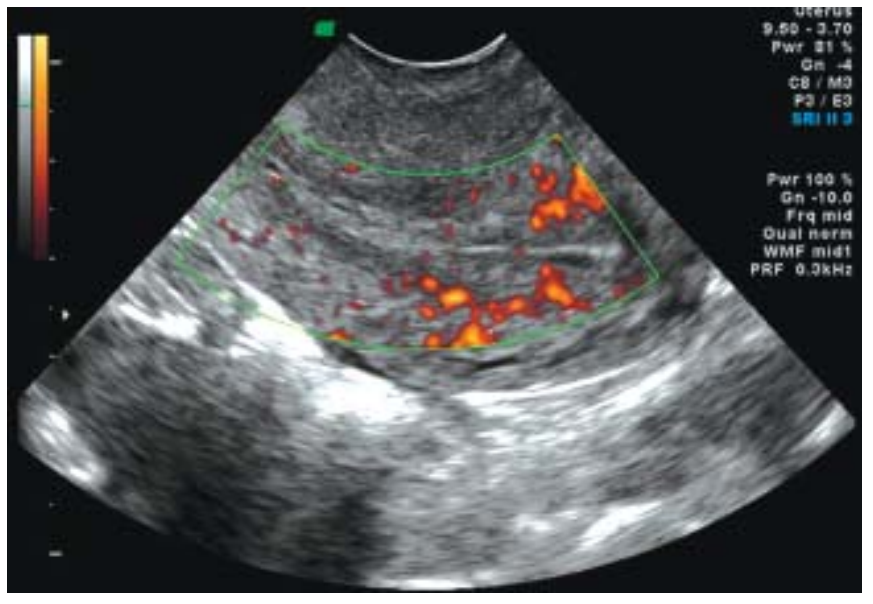

Fig. 13: endometrial vascularity zone 3

zone 1 and $13.4 \%$ for zone 2 vascularity. The conception rates with zone 3 and 4 the pregnancy rates were comparable and were 35.8 and $38.3 \%$ respectively. 
Three-dimensional and Power Doppler Ultrasound of the Follicle and Endometrium on the Day of hCG Administration

Zone of Vascularity: (1025 cases)

\begin{tabular}{lrrrr}
\hline Vascular zone & 1 & 2 & 3 & 4 \\
Conc. & 10 & 52 & 100 & 84 \\
NonConc. & 125 & 336 & 181 & 137 \\
\hline Total & 135 & 388 & 281 & 221 \\
\hline
\end{tabular}

Zaidi et al found that absence of flow in the endometrial and subendometrial zones on day of HCG indicate total failure of implantation. ${ }^{16}$ The vessels that reach the endometrium are the spiral arteries. The pulse Doppler of these arteries should have an RI of between 0.6 and 0.8 and PI of between 1.1 and 2.3 for the endometrium to be called mature for implantation (Fig. 14). Moreover, the pulse Doppler analysis of the uterine artery waveform is done and its RI should be not more than 0.9 and PI should be $<3.2$ (Fig. 15). Several authors have shown that the optimum uterine receptivity was obtained when average pulsatility index of the uterine artery was between 2 and 3 on the day of transfer or on the day of hCG. ${ }^{17-19}$ Coulam et al have also shown that no pregnancy was achieved after embryo transfer when uterine artery PI was above 3.3 in an IVF program. ${ }^{20}$ Tsai and colleagues ${ }^{19}$ evaluated the prognostic value of uterine perfusion on day of hCG for IUI cycles and showed that no pregnancy occurred when the pulsatility index of ascending branch of uterine artery was $>3$. Fecundity rate was $18 \%$ when PI $<2$ and 19.8\% when between 2 and 3. This probably can be explained on the basis that the uteri having fibroids or adenomyosis show fairly high uterine artery blood flow velocities but lower resistance indices. A study by Cacciatore et al suggest that implantation is unlikely when PI is $>3.3$ and RI $>0.95$ or when no velocities are seen at the end of the diastole. ${ }^{21}$ Though uterine artery impedance is usually low in superovulated cycles. In our unpublished data of more than 1000 IUI cycles, when color Doppler studies were done 12 hours before HCG injection, we have found no conceptions when uterine artery PI $>3.5$.

Then when the endometrial and the uterine artery parameters are optimum as described above, the volume of the endometrium with power Doppler is acquired and then the endometrial volume is calculated by vocal, tracing the outer edge of the hyperechoic outer rim of the endometrium and accept the volume (Fig. 16). The endometrium up to the internal os is taken into calculation. For accurate measurements, a good contrast in the image is necessary. Select smaller angles of rotation for vocal. Fluid in the endometrial cavity can be a source of error. For endometrial volume the inter CC definition of internal os and (interobserver variation) was 0.82 and intra CC (intraobserver variation) was 0.90 , the chief source of error being definition of endometrial margins. $^{1}$

Our study ${ }^{27}$ showed that at endometrial volume of $<2$ cc no pregnancies occurred. With endometrial volume of 2 to 3 cc

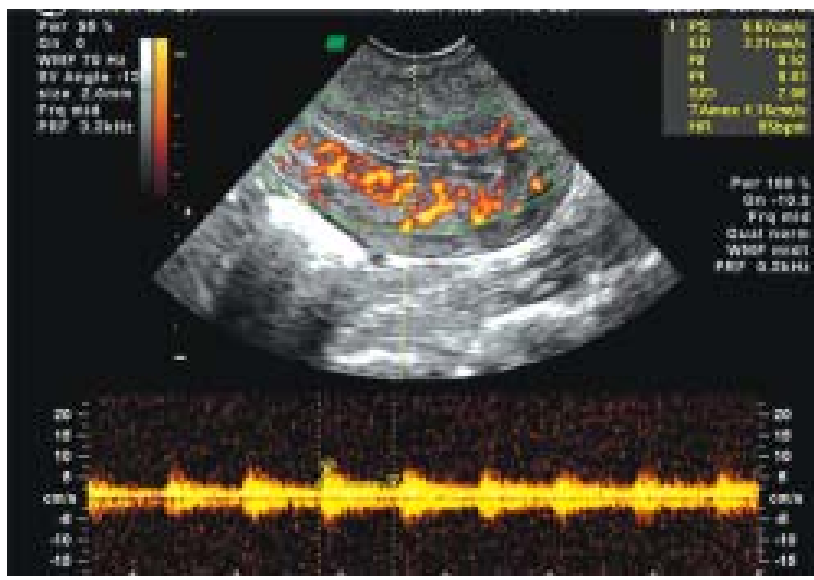

Fig. 14: Pulse Doppler of endometrial vascularity

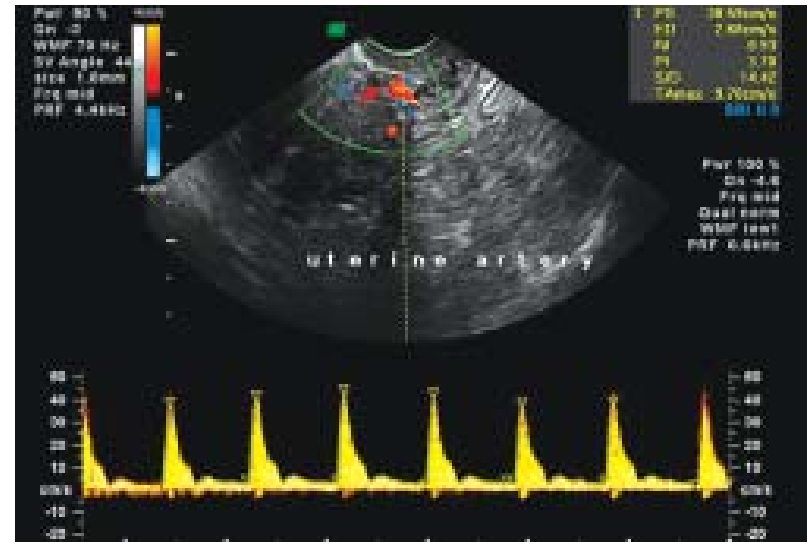

Fig. 15: Preovulatory uterine artery waveform

only $16.66 \%$ of patients conceived, between 3 and 5 cc $47 \%$ and when the endometrial volume was between 5 and 7 cc $61.5 \%$ patients conceived.

\section{Endometrial volume: (500 cases)}

\begin{tabular}{lrrrrr}
\hline Endo.Vol & $<2$ & $2-3$ & $3.1-5$ & $5.1-7$ & $>7$ \\
Conc. & 0 & 26 & 70 & 67 & 41 \\
NonConc. & 20 & 132 & 78 & 42 & 24 \\
\hline Total & 20 & 158 & 148 & 109 & 65 \\
\hline
\end{tabular}

Endometrial volume 3D US volume calculation of the endometrium may help to correlate the cycle outcome with quantitative parameter rather than endometrial thickness. ${ }^{6} \mathrm{~A}$ study by Raga et $\mathrm{al}^{22}$ shows pregnancy and implantation rates were significantly lower when endometrial volume $<2 \mathrm{ml}$, while no pregnancy was achieved when endometrial volume was $<1 \mathrm{ml}$. Study by Kupesic et al also shows no pregnancy when endometrial volume was $<2 \mathrm{ml}$, or when exceeded $8 \mathrm{ml} .{ }^{23}$ For the same calculated volume, volume histogram is switched on and it calculates the endometrial VI, FI and VFI (Fig. 17 and 18). In our series ${ }^{27}$ the endometrial VI values were not very 


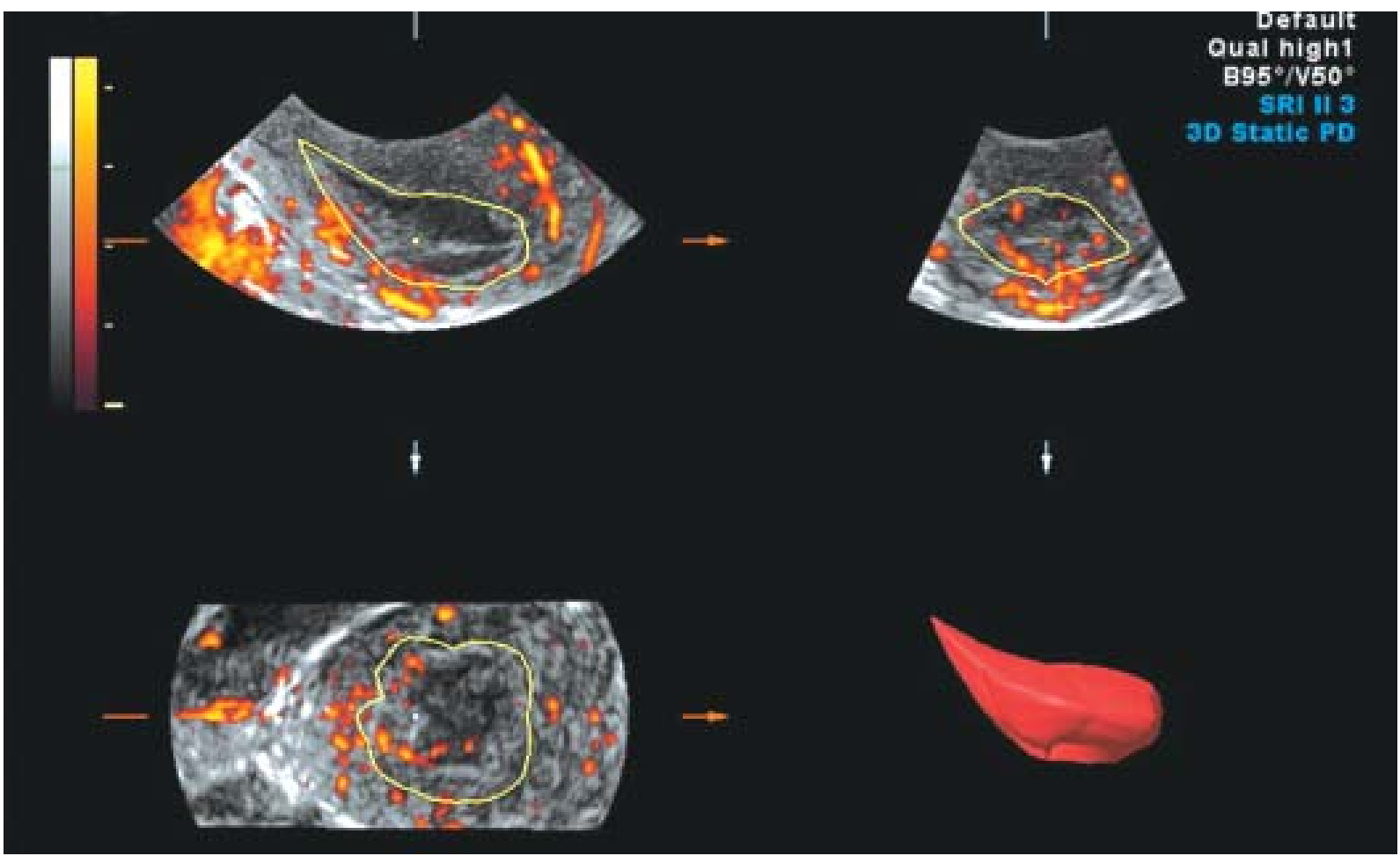

Fig. 16: Calculating endometrial volume by vocal

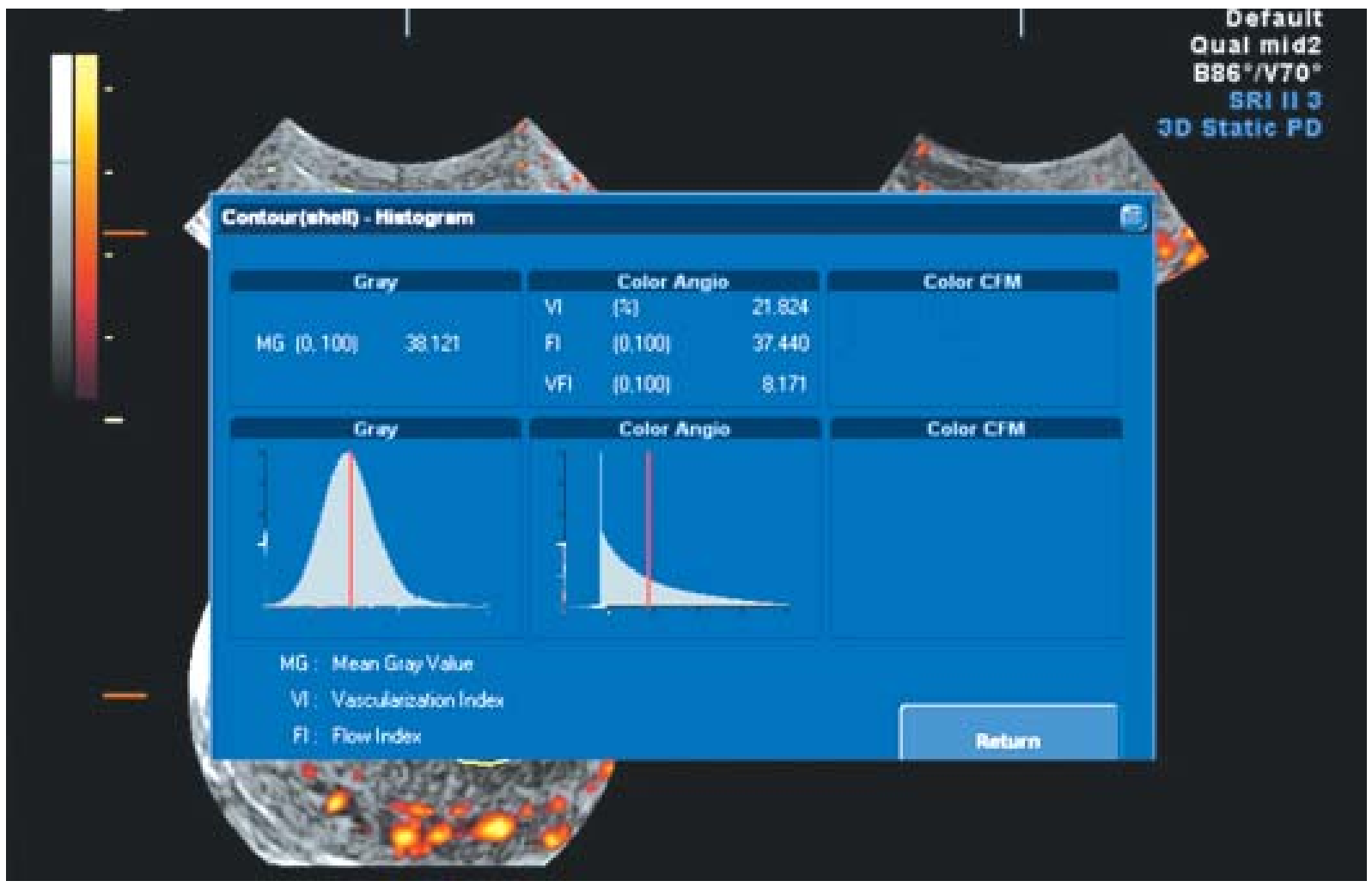

Fig. 17: Histogram of endometrium showing VI, FI and VFI values 


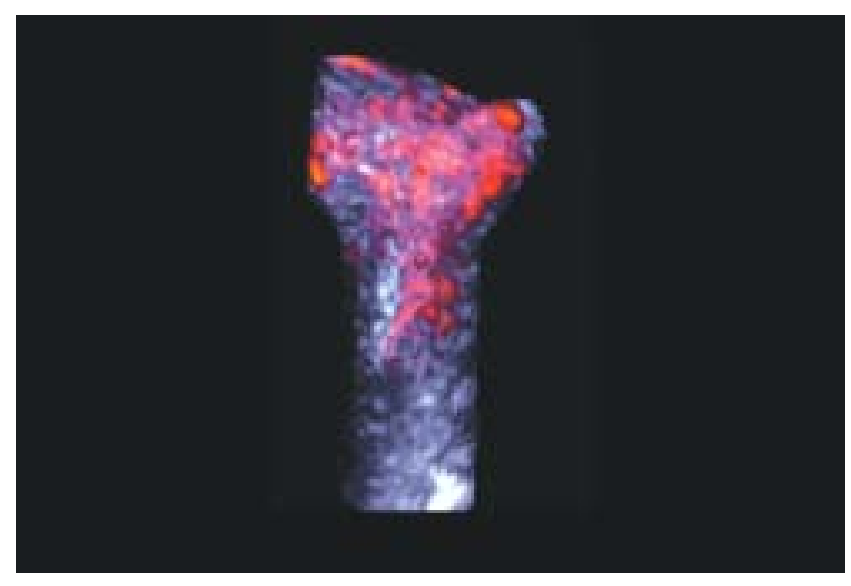

Fig. 18: Glass body mode of endometrial 3D power Doppler vascularity

conclusive. Endometrial FI when was $<20$, only $23 \%$ of patients showed conception, between 20 and 40 it was almost $50 \%$ but when FI was more than $40,68 \%$ of patients showed conception.

\section{Endometrial FI : (500 cases)}

\begin{tabular}{lrrrr}
\hline Endo. FI & $<20$ & $20-30$ & $30.1-40$ & $>40$ \\
Conc. & 37 & 68 & 75 & 34 \\
Non Conc. & 125 & 76 & 68 & 17 \\
\hline Total & 162 & 144 & 143 & 51 \\
\hline
\end{tabular}

Endometrial VFI when was $>20$ the conception occurred in $71.2 \%$ of patients and when VFI was $<1.0$ no conception was seen. Though between VFI 5 and 20 the percentage of conception was 49 to $56 \%$ (Fig. 19).

\section{Endometrial VFI: ( 500 cases)}

\begin{tabular}{lrrrrr}
\hline Endo.VFI & $<2$ & $2-5$ & $5.1-12$ & $12.1-20$ & $>20$ \\
Conc. & 00 & 96 & 64 & 45 & 09 \\
NonConc. & 44 & 136 & 66 & 36 & 04 \\
\hline Total & 44 & 232 & 130 & 81 & 13 \\
\hline
\end{tabular}

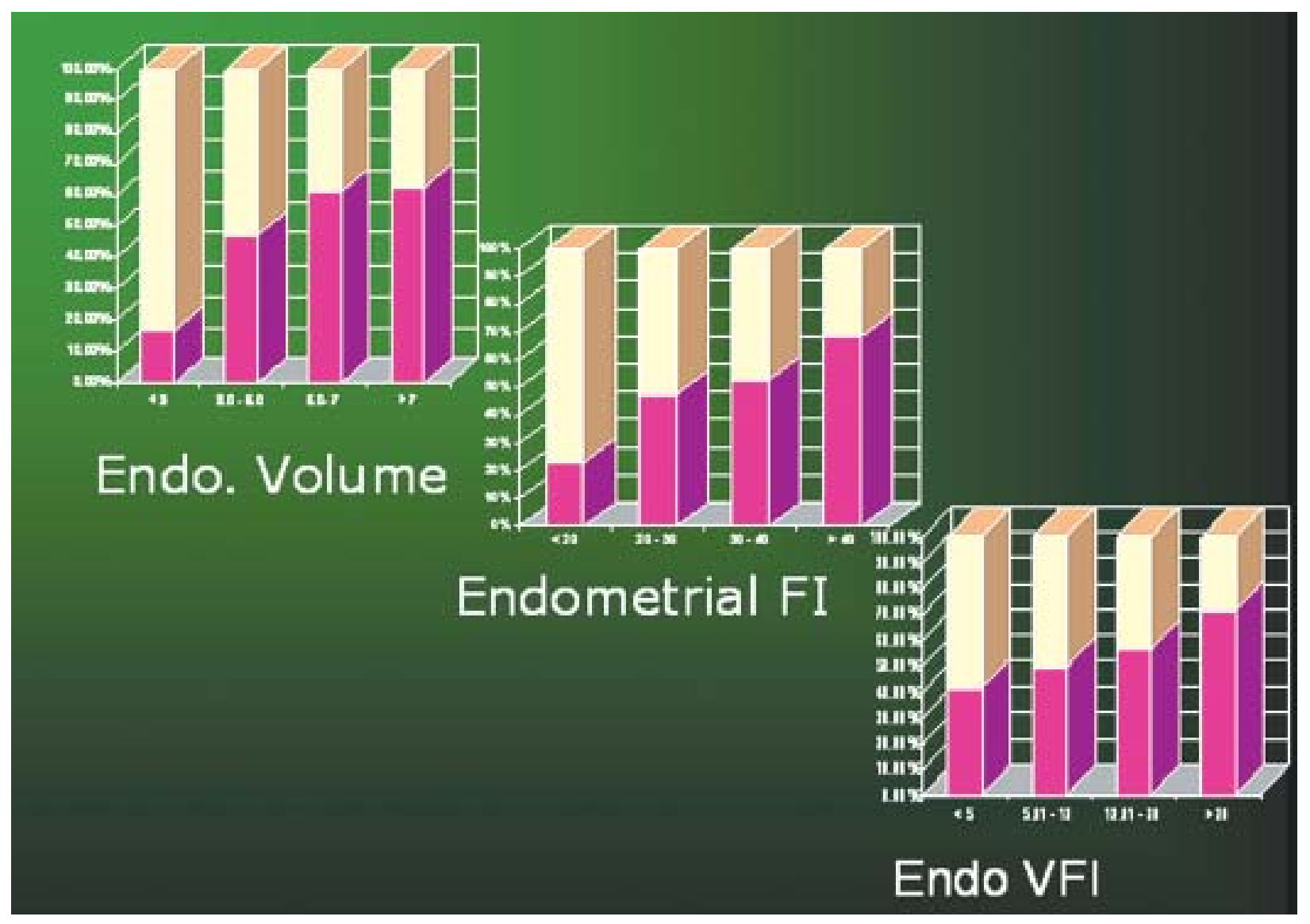

Fig. 19: Pre HCG endometrial volume and 3D-PD values 
A scoring system reported by Kupesic et al, ${ }^{23}$ for uterine receptivity, done on the day of embryo transfer shows that subendometrial FI $<11$ was a cut off limit. (Subendometrial indices are calculated in the same way from the endometrial volume as we calculate the perifollicular indices from the follicular volume, i.e. by shell volume of $2 \mathrm{~mm}$ thickness). No pregnancies occurred when it was $<11$ and the conception group showed its values of $13.2+2.2$. This values differ from our values probably because we have taken the whole endometrium as the volume as compared to the calculations made for the subendometrial layers here, but is common in both that higher FI values are associated with higher pregnancy rates.

Where as $\mathrm{Ng}$ et $\mathrm{al}^{24}$ documented a low endometrial VI and VFI in pregnant group on the day of oocyte retrieval and also a nonsignificant trend of higher implantation and pregnancy rates in patients with absent subendometrial and endometrial flow. This probably can be explained on the basis that hCG administration/LH peak causes increased uterine artery resistance and hence decrease in endometrial perfusion also on the day of oocyte retrieval. This also correlates with the observation made by $\mathrm{Ng}$, et $\mathrm{al}^{25}$ which says that subendometrial vascularization flow indices are significantly lower in patients with uterine artery RI $>0.95$. Though they concluded that number of embryos replaced and the endometrial VFI were the only two predictive factors for pregnancy. Wu et al ${ }^{26}$ reported that endometrial VFI was more reliable than VI and FI, and best prediction rate was achieved by VFI cut off value of $>0.24$.

\section{CONCLUSIONS}

3D ultrasound is much accurate for volume assessment both for follicle and the endometrium, which are much more reliable parameters than follicular diameter or endometrial thickness. The presence of cumulus which can be confirmed by 3D US increases the surety of the presence of a mature ovum in the follicle. The 3D power Doppler gives idea about the global vascularity of the follicle and the endometrium. Though still larger studies are needed to establish more precise values for follicular and endometrial VI, FI and VFI, the results are fairly promising. We can hope to understand the follicular and endometrial physiological status better with these parameters and achieve better pregnancy rates with ART procedures and reduce the span of unexplained infertility.

\section{REFERENCES}

1. Kyei-Mensah A, Zaidi J, Pittrof R, Shaker A, Campbell S, Tan SL. Transvaginal three dimensional ultrasound: accuracy of follicular volume measurements. Fertil Steril 1996;65:371-76.

2. Kupesic S, Kurjak A. Uterine and ovarian perfusion during the periovulatory period assessed by transvaginal colour Doppler. Fertil Steril 1993;3:439-43.
3. Nargund G, Doyle PE, Bourne TH, et al. Ultrasound-deviced indices of follicular blood flow before HCG administration and prediction of oocyte recovery and preimplantation embryo quality. Hum Reprod 1996;11:2512-17.

4. Nargund G, Bourne TH, Doyle PE, et al. Association between ultrasound indices of follicular blood flow, oocyte recovery and preimplantation embryo quality. Hum Reprod 1996;11:109-13.

5. Wittmack FM, Kreger DO, Blasco L, Tureck RW, Mastroianni L Jr Lessey BA. Effect of follicular size on oocyte retrieval, fertilization, cleavage and embryo quality in in vitro fertilization cycles: a 6 year data collection. Fertil Steril 1994;62:1205-10.

6. Kyei-Mensah A, Zaidi J, Pittrof R, Shaker A, Campbell S, Tan SL. Transvaginal three dimensional ultrasound reproducibility of ovarian and endometrial volume measurements. Fertil Steril 1996;66:718-22.

7. Feichtinger W. Transvaginal three dimensional imaging for evaluation and treatment of infertility. In Merz E (Ed): 3D ultrasound in obstetrics and Gyneacology. Philadelphia: Lipincott Williams \& Wilkins, 1998;37-43.

8. Poehl M, Hohlagschwandtner M, Doerner V, Dillinger B, Feichtinger W. Cumulus assessment by three dimensional ultrasound for in vitro fertilization. Ultrasound Obstet Gynecol 2000;16:251-53.

9. Wu MH, Tsai SJ, Pan HA, Hsiao KY, Chang FM. Three dimensional power Doppler imaging of ovarian stromal blood flow in women with endometriosis undergoing in vitro fertilization. Ultrasound Obstet Gynecol 2003;21:480-85.

10. Vlaisavljevic V, Reljic M, Gavric Lovrec V, Zazula D, Sergent $\mathrm{N}$. Measurement of perifollicular blood flow of the dominant preovulatory follicle using three dimensional power Doppler. Ultrasound Obstet Gynecol 2003;22:520-26.

11. Kupesic S, Kurjak A. Prediction of IVF outcome by three dimensional ultrasound. Hum Reprod 2002;17:950-55.

12. Merce LT. Ultrasound markers of implantation. Ultrasound Rev Obstet Gynecol 2002;2:110-23.

13. Merce LT, Barco MJ, Kupesic S, Kurjak A. 2D and 3D power Doppler ultrasound from ovulation to implantation. In Kurjak A, Chervenak F (Eds): Textbook of perinatal medicine. London: Parthenon Publishing, 2005.

14. Kupesic S, Kurjak A, Vujisic S, Petrovic Z. Luteal phase defect: Comparison between Doppler velocimetry, histological and hormonal markers. Ultrasound Obstet Gynecology 1997;9:10512.

15. Applebaum M. The 'steel' or 'teflon' endometrium—ultrasound visualization of endometrial vascularity in IVF patients and outcome. Presented at The third World Congress of Ultrasound in Obstetrics and Gynaecology. Ultrasound Obstet Gynecol 1993;3 (suppl 2):10.

16. Zaidi J, Campbell S, Pittrof R, Tan SL. Endometrial thickness, morphology, vascular penetration and velocimetry in predicting implantation in an in vitro fertilization program. Ultrasound Obstet Gynecol 1995;6:191-98.

17. Steer CV, Campbell S, Tan SL, et al. The use of transvaginal colour flow imaging after in vitro fertilization to identify optimum uterine conditions before embryo transfer. Fertil Steril 1992;57:372-76. 
18. Zaidi J, Pittrof R, Shaker A, Kyei-Mensah A, Campbell S, Tan SL. Assessment of uterine artery blood flow on the day of human chorionic Gonadotropin administration by transvaginal colour Doppler ultrasound in an in vitro fertilization program. Fertil Steril 1996;65:377-81.

19. Tsai YC, Chang JC, Tai MJ, Kung FT, Yang LC, Chang SY. Relationship of uterine perfusion to outcome of intrauterine insemination. J Ultrasound Med 1996;15:633-36.

20. Coulam CB, Stern JJ, Soenksen DM, Britten S, Bustillo M. Comparison of pulsatility indexes on the day of oocyte retrieval and embryo transfer. Hum Reprod 1995;10:82-84.

21. Cacciatore B, Simberg N, Fusaro P, Tiitinen A. Transvaginal Doppler study of uterine artery blood flow in in vitro fertilization embryo transfer cycles. Fertil Steril 1996;66:130-34.

22. Raga F, Bonilla-Musoles F, Casan EM, Klein O, Bonilla F. Assessment of endometrial volume by three dimensional ultrasound prior to embryo transfer: clues to endometrial receptivity. Hum Reprod 1999;14:2851-54.

23. Kupesic S, Bekavac I, Bjelos D, Kurjak A. Assessment of endometrial receptivity by transvaginal colour Doppler and three dimensional power Doppler ultrasonography in patients undergoing in vitro fertilization procedures. J Ultrasound Med 2001;20:125-34.

24. Ng EH, Chan CC, Tang OS, Yeung WS, Ho PC. The role of endometrial and subendometrial blood flows masured by three dimensional power Doppler ultrasound in prediction of pregnancy during IVF treatment. Hum Reprod 2006;21(1):16470 .

25. Ng EH, Chan CC, Tang OS, Yeung WS, Ho PC. Relationship between uterine blood flow and endometrial and subendometrial blood flows during stimulated and natural cycles. Fertil Steril 2006;85(3):721-27.

26. Wu HM, Chiang CH, Huang HY, Chao AS, Wang HS, Soong YK. Detection of subendometrial vascularization flow index by three dimensional ultrasound may be useful for predicting pregnancy rate for patients undergoing in vitro fertilizationembryo transfer. Fertil Steril 2003;79(3):507-11.

27. Panchal SY, Nagori CB. Can 3D PD be a better tool for assessing the pre HCG follicle and endometrium? A randomized study of 500 cases. Presented at 16th World Congress on Ultrasound in Obstetrics and Gynecology, 2006, London. J Ultrasound Obstet Gynecol 2006;28(4):504. 